\title{
Carnivore diversity at a montane rainforest site in Ecuador's Gran Sumaco Biosphere Reserve
}

\author{
Anne-Marie C. Hodge and Brian S. Arbogast
}

\begin{abstract}
Ecuador harbours a diverse assemblage of tropical mammals, yet the natural history and local-scale distributions of many species remain poorly understood. We conducted the first systematic camera-trap survey of terrestrial mammalian carnivores at Wildsumaco Wildlife Sanctuary, a mid-elevation $(1,250-1,450 \mathrm{~m})$, montane rainforest site on the slopes of Sumaco Volcano, in the heart of the Tropical Andes biodiversity hotspot. We quantified trap success, latency to detection and temporal activity patterns for each species detected. We recorded nine carnivore species (four felids, two procyonids and three mustelids), including the first verified record of the jaguarundi Puma yagouaroundi in the region. These species comprise one-third of all terrestrial carnivore species known to occur in Ecuador and $82 \%$ of those thought to occur at mid-elevation. All except one of the carnivores we detected have reported elevational ranges $\leq 1,500 \mathrm{~m}$; the one exception, the puma Puma concolor, occurs throughout mainland Ecuador at $0-4,500 \mathrm{~m}$. No cloud forest or highland species (i.e. those with a reported lower elevational limit of $\geq 1,500 \mathrm{~m}$ ) were detected. Trap success was highest, and latency to detection smallest, for the margay Leopardis wiedii, and temporal activity patterns for all species were consistent with those reported previously in the literature. Our results demonstrate that the midelevation montane rainforests of Sumaco Volcano support an exceptionally high diversity of co-existing mammalian carnivores, many of which appear to be near their upper elevational limits, and emphasize the conservation value of this area.
\end{abstract}

Keywords Biodiversity, camera survey, Ecuador, Felidae, mammals, South America, Tropical Andes, wildlife monitoring

\footnotetext{
Anne-Marie C. Hodge* (Corresponding author) and Brian S. Arbogast Department of Biology and Marine Biology, University of North Carolina, 601 S. College Road, Wilmington, NC, 28405 USA

E-mail ahodge@uwyo.edu

${ }^{*}$ Current address: Department of Zoology and Physiology, University of Wyoming, 1000 E. University Ave., Laramie, WY, 82070 USA

Received 6 October 2014. Revision requested 11 November 2014. Accepted 20 January 2015. First published online 25 May 2015.
}

\section{Introduction}

T istorically, the cryptic and often nocturnal nature of 1 many Neotropical carnivores has made them challenging to study in the wild (Kelly, 2008). As a result, knowledge of which and how many species co-exist at local scales is typically sparse (Di Bitetti et al., 2010). Midelevation sites are especially interesting locations in which to investigate distributional patterns in Neotropical carnivores as these sites are predicted to have relatively high species diversity and the potential to support novel species assemblages not found at either higher or lower elevations (Shepherd \& Kelt, 1999; McCain, 2005; Burneo, 2007). It is difficult to determine the degree to which these predictions hold true, however, because there is a paucity of empirical studies of mid-elevation Neotropical carnivore communities. Detailed studies of these communities therefore offer an opportunity to document species diversity and community membership, and to test hypotheses related to patterns of species co-existence in space and time at a local scale. Documenting distributional patterns of Neotropical carnivore diversity and characterizing species assemblages at the local scale are also important from a conservation perspective. Carnivore populations depend upon the health and abundance of prey populations for sustenance, and thus carnivores can be sensitive to environmental disturbance and habitat degradation and loss (Woodroffe \& Ginsburg, 1998; Laidlaw, 2000; Cardillo et al., 2004); for example, large-bodied carnivores, which typically occur at low population densities, are often lost from habitat fragments that fall below a critical size (Michalski \& Peres, 2005). Both quality and quantity of habitat have direct and indirect effects on the geographical distribution and local-scale occupancy patterns of mesopredator populations. Mesopredators maintain their populations through a fine balance between top-down constraints from larger carnivores and bottom-up constraints in the form of resource availability (Elmhagen \& Rushton, 2007). Finally, anthropogenic disturbance causes many animal populations to experience range contractions (Poley et al., 2014), creating discontinuous or patchy regional occupancy patterns. Thus, detailed local-scale studies also provide an opportunity to investigate the environmental conditions that may facilitate the cooccurrence of the greatest number of carnivore species. Remotely triggered camera-trapping has shown to be a useful method for documenting the presence, population 
status, and activity patterns of elusive Neotropical carnivores (Gutiérrez-Gonzalez et al., 2012; Kilshaw et al., 2015; Quiroga et al., 2014).

Here we present the first systematic camera survey of mammalian carnivore diversity on Sumaco Volcano, Ecuador, which is within the Tropical Andes global biodiversity hotspot (Brooks et al., 2002; Jenkins et al., 2013). The mid-elevation position of our study site, its proximity to the borders of a National Park, the mixed-use landscape in the surrounding matrix, the presence of both primary and mature secondary growth forest, and the abundance of prey species documented during pilot studies all underlie the importance of documenting carnivore species diversity and detection rates in the region.

\section{Study area}

We worked at Wildsumaco Wildlife Sanctuary, a private conservancy within the c. 932,000 ha Gran Sumaco Biosphere Reserve. The c. 500 ha Sanctuary is located at mid-elevation $(1,250-1,450 \mathrm{~m}), 8 \mathrm{~km}$ from the southern boundary of Sumaco Napo-Galeras National Park (c. 205,000 ha; Fig. 1), which comprises two disjunct protected areas, Sumaco to the north and Cordillera Galeras to the south. The upper slopes of Sumaco Volcano $(>1,600 \mathrm{~m})$ are within the Park, and the dominant vegetation types are cloud forest $(1,600-3,000 \mathrm{~m})$ and páramo $(>3,000 \mathrm{~m})$. The Sanctuary contains both secondary and primary rainforest and is situated within a larger matrix of rainforest and intermittent livestock pastures and rural homesteads. It is typified by montane rainforest (both primary and secondary), yet it lies in close proximity (c. $8 \mathrm{~km}$ and $150 \mathrm{~m}$ in elevation) to the cloud forest biome that dominates much of Sumaco Volcano above $1,600 \mathrm{~m}$.

\section{Methods}

Data were collected during July 2010-June 2011, using remote camera transects (Silver et al., 2004). Digital Reconyx RC55 (Reconyx, Inc., Holmen, USA) cameras were deployed with both motion and infrared sensors enabled. Cameras were mounted on tree trunks, 0.5-1.0 m from the ground. When possible, two cameras were installed at each station to increase the probability of both sides of a passing animal's body being photographed. Simultaneous captures by paired cameras, or captures of individuals of the same species occurring $<1$ hour apart, were considered non-independent and were therefore pooled for analysis.

Each survey lasted 9-12 weeks, and each focused on a different forest transect. Transects and sampling periods were as follows: F.A.C.E. Trail, 7 July-10 October $2010(1,065$ trap nights); Benavides Trail, 8 October-3 December 2010 (992

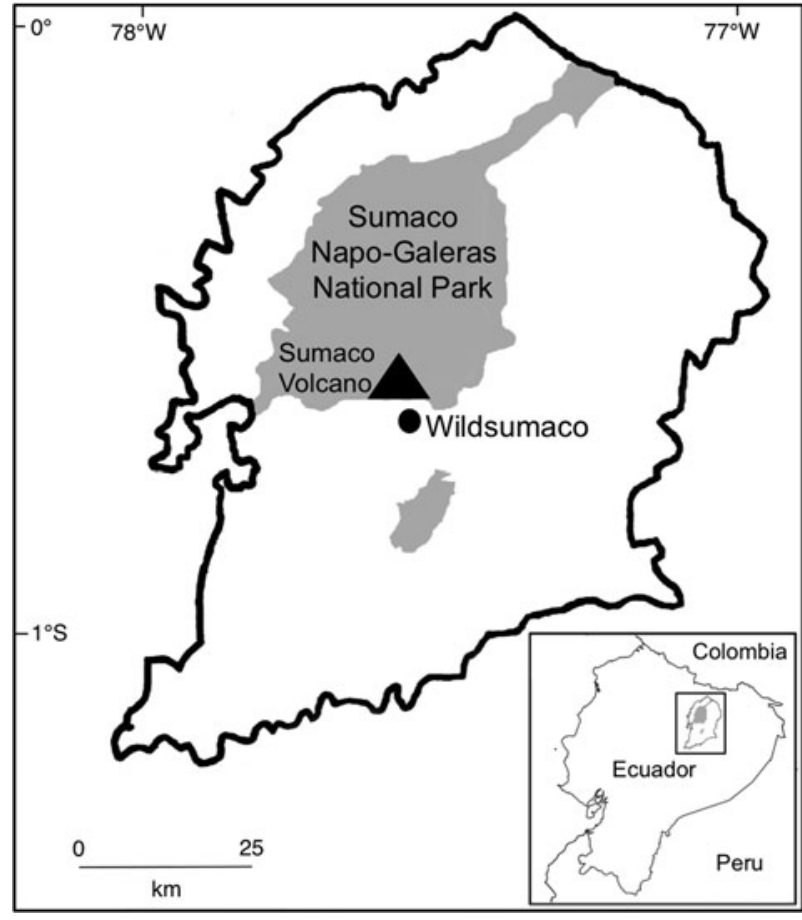

FIG. 1 Location of Wildsumaco Wildlife Sanctuary in Gran Sumaco Biosphere Reserve, Ecuador. The rectangle on the inset shows the location of the main map in Ecuador. Figure modified from Ruiz (2010).

trap nights); Waterfall Trail, 16 December 2010-17 February 2011 (1,120 trap nights); and Puffbird Trail, 20 February-27 May 2011 (864 trap nights). Camera stations were located $250-300 \mathrm{~m}$ apart in an approximately linear fashion, following footpaths and game trails, as the steep topography precluded the use of a regularly spaced grid. For each survey, 18-25 cameras were utilized.

Tirira (1999) was the primary reference for species identification. When a species was detected for the first time, the authors classified the animal independently, and photographs were distributed to multiple colleagues for verification of species identity. Partial photographs of individuals were considered detections only if diagnostic features were clearly present and unambiguous.

Trap success was calculated as the number of capture events for each species per trap night for each transect (Gerber et al., 2010). Latency to initial detection was quantified for each species by using the date/time stamps on the photographs to determine the number of trap nights between the initiation of sampling on a transect and the first record of a species on that transect (Gompper et al., 2006). We documented temporal activity patterns for each species by recording the proportion of detections that occurred at dawn (1 hour before to 1 hour after sunrise, 05.00-07.00), during the day (07.00-17.30), at dusk (1 hour before to 1 hour after sunset, 17.30-19.30), and at night (19.3005.00), following Lucherini et al. (2009). The close 
proximity of the Sanctuary to the equator means that sunrise and sunset times do not vary substantially throughout the year. Chi-square $\left(\chi^{2}\right)$ tests were used to evaluate the null hypothesis that the proportion of captures of each species with $>_{1}$ detections would be equal in each time category.

\section{Results}

During the four surveys $(4,041$ trap nights in total) we recorded nine of the $11(81.8 \%)$ species of terrestrial mammalian carnivores that are reported to occur in this elevational zone $(1,250-1,450 \mathrm{~m})$ in eastern Ecuador, and one-third (nine of 27) of all species of terrestrial mammalian carnivores that occur nationwide (Tirira, 1999). The recorded species represented three carnivore families: Felidae, Mustelidae and Procyonidae (Plate 1). The four felids were the margay Leopardus wiedii, ocelot Leopardus pardalis, jaguarundi Puma yagouaroundi, and puma Puma concolor, and this was the first verified record of $P$. yagouaroundi for this region. The three mustelids were the greater grison Galictis vittata, tayra Eira barbara, and long-tailed weasel Mustela frenata. The two procyonids were the South American coati Nasua nasua and kinkajou Potos flavus.

Trap success was highest for L. wiedii (0.0255), and for the other species it was 0.0003-0.0017 (Table 1). Leopardus wiedii also had the highest site occupancy and was detected on each of the four transects. In contrast, nearly all of the other species were detected on only one of the four transects; for example, $P$. concolor, P. yagouaroundi, $L$. pardalis, and G. vittata were each recorded on the F.A. C.E. Trail only, M. frenata was recorded on the Waterfall Trail only, and N. nasua and P. flavus were recorded exclusively on the Benavides Trail. Eira barbara was recorded on three of the four transects (F.A.C.E., Waterfall, and Puffbird Trails). Latency to detection was 4-74 days, with the lowest mean value recorded for $L$. wiedii ( 4 days), and the highest for P. yagouaroundi (74 days; Table 1).

$\chi^{2}$ for each carnivore species detected more than once rejected the null hypothesis that species are equally active during all temporal periods $(\mathrm{P}<0.0001$ for all species). Puma concolor, $L$. wiedii and $L$. pardalis were primarily nocturnal. For E. barbara trap success was equal during the day and at dusk but the species was never detected during the night or at dawn, and therefore it was categorized as diurnal.

\section{Discussion}

This was the first systematic camera-trap survey of terrestrial carnivores in the Gran Sumaco Biosphere's midelevation montane forest. Our results validate cameratrapping as an effective method for investigating species occupancy in densely forested habitats in regions with steeply sloped topography. We documented a highly diverse carnivore assemblage that includes a minimum of nine species spanning two orders of magnitude in body mass, and represents one-third of all of Ecuador's terrestrial carnivore species (Table 1, Plate 1).

Our results demonstrate that montane rainforest habitats in mid-elevation zones of the eastern Andes can support rich assemblages of carnivores; in this case the assemblage was composed almost exclusively of taxa with Amazonian affinities, despite the proximity of our study site to the montane rainforest-cloud forest ecotone on Sumaco Volcano. Although the literature suggests that overlap between high- and low-elevation species can lead to midelevation peaks in species diversity (Colwell et al., 2004; McCain, 2005; Kluge et al., 2006), no high-elevation species (i.e. those with a reported lower elevational limit of $\geq 1,500$ $\mathrm{m}$ and known from the nearby cloud forest biome of Sumaco Volcano) were detected in our surveys. With the exception of the wide-ranging $P$. concolor (which occurs at o-4,500 $\mathrm{m}$ in Ecuador), all of the terrestrial carnivores we detected have upper elevation records of $\leq 1,500 \mathrm{~m}$ (Tirira, 1999) and can be characterized as low- or low-tomid-elevation species. Thus, the high species diversity we observed was not a result of an overlap of high- and lowelevation species but may be attributed to a concentration of the latter.

Although some species were detected only once, the fact that they pass through this area even transiently, in addition to Sumaco Volcano's unique position on the far eastern edge of the Andean cordillera in Ecuador, indicates that the region could be an important Amazonian-Andean corridor as well as being a primary habitat zone for many other species. As such, these mid-elevation sites should be targeted for surveys and given high priority in conservation planning. This finding has important implications for conservation: as global climate change drives progressive shifts in climate envelopes, the potential spread of Amazonian species to higher elevations could make mid-elevation sites important potential refuges from lowland deforestation and declines in suitable climatic conditions and habitat at low elevations.

The high trap success for $L$. wiedii is another important outcome of this study. Previous studies have reported lower detection rates for the species (Di Bitetti et al., 2010). Goulart et al. (2009) reported trap success of only 0.003, and two surveys reported in Tobler et al. (2008) had trap success of only 0.0014 and 0.0056 . The trap success of 0.0255 reported here for $L$. wiedii, which included 12 individuals (Hodge, 2012), has implications for future management efforts for the species, as it indicates that the population of $L$. wiedii in this area appears to be exceptional either in its abundance or in behavioural patterns that facilitate detectability by camera traps (Vanderhoff et al., 2011; Hodge, 2014). Both of the potential explanations for these 

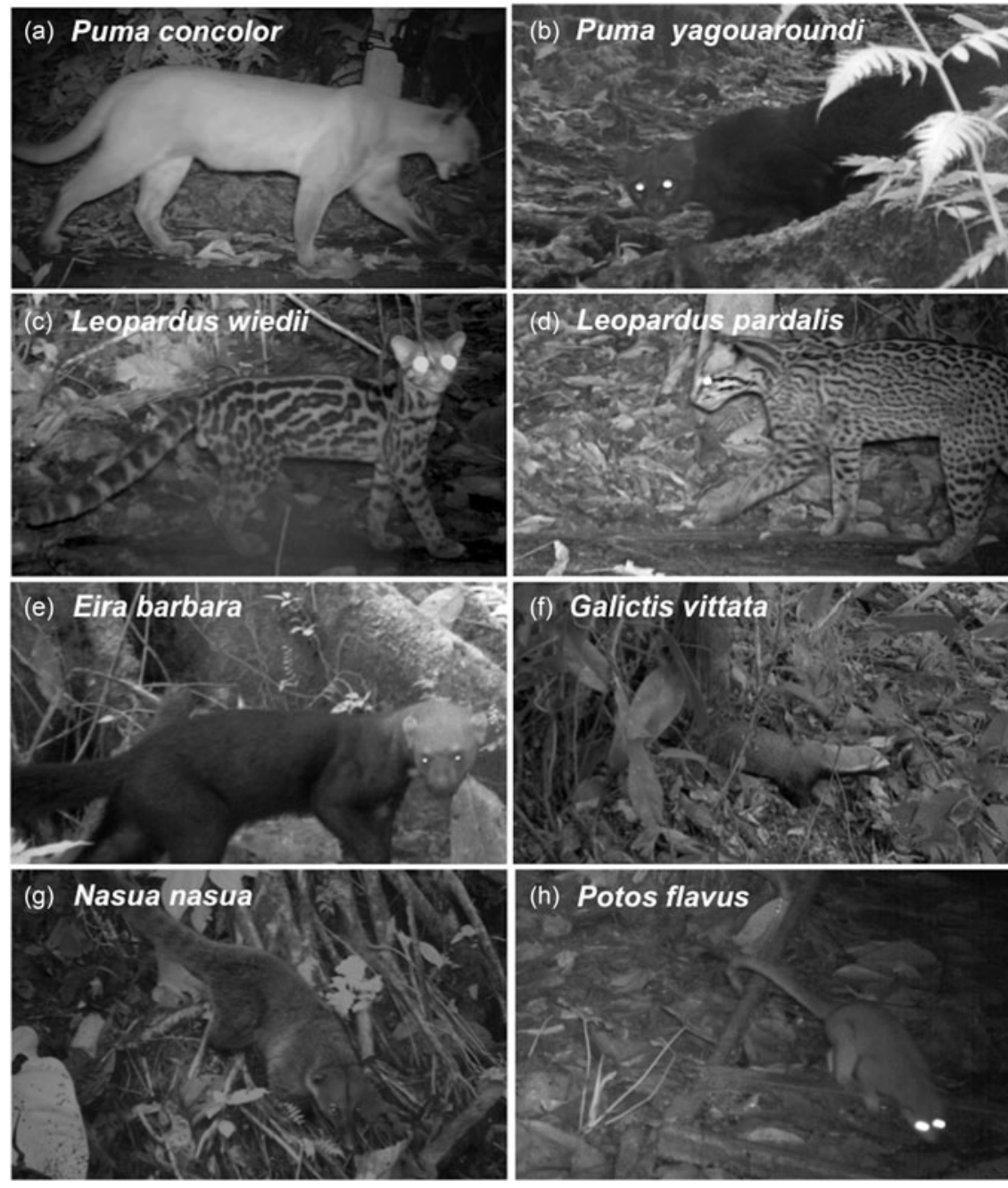

Plate 1 Representative camera trap photographs of the four species of felids (a-d), two of the three species of mustelids (e \& $f$ ) and both species of procyonids $(\mathrm{g} \& \mathrm{~h})$ recorded in surveys of Wildsumaco Wildlife Sanctuary (Fig. 1). Not shown is the long-tailed weasel Mustela frenata. results indicate that Wildsumaco Wildlife Sanctuary is an excellent locality from which to gain further insights into the natural history of this little-known tropical felid.

Each of the three largest felids ( $P$. concolor, $P$. yagouaroundi and $L$. pardalis) was detected exclusively on the F.A. C.E Trail. Repeated detections of the same individual P. concolor over time indicated that this forest patch was part of a regularly visited home range and not just a transitory zone. The area around this trail contains the most extensive and continuous primary forest in the Sanctuary. Although we did not find evidence that the Sanctuary itself is supporting entire home ranges for the larger carnivore species, the detection of these species on the property demonstrates that it is a functional part of the larger landscape matrix available to these species.

This finding may have important implications for restoration ecology because it suggests that even after a forest has been allowed to regenerate it may neither provide habitat for the same species assemblages that were present prior to disturbance nor support the same species diversity (Barlow et al., 2007; Gibson et al., 2011). Further research on the details of carnivore habitat selection in this region will be useful in bringing these issues to light.

Two species that occur at similar elevations in the Gran Sumaco region (Tirira, 1999) were not recorded in our camera-trap surveys: the jaguar Panthera onca and the bush dog Speothos venaticus. Wildsumaco Wildlife Sanctuary is near the upper elevational limit recorded for $S$. venaticus $(1,900 \mathrm{~m}$; Beisiegel \& Zuercher, 2005) and is also close ( $<2 \mathrm{~km}$ in places) to a small village, either of which could explain the failure to detect $S$. venaticus there. The extensive home range requirements of $P$. onca and the relatively modest size of the Sanctuary could also be a factor in the rarity of the species at this site, resulting in low detection probabilities using remote cameras. Extensive home range requirements did not exclude the presence of $P$. concolor, however, so elevational limits, historical persecution by people, infrequent travel through the site, or other undetermined factors probably also played a role.

The low trap success for species such as M. frenata and $P$. flavus is probably attributable to low detectability rather than rarity; $P$. flavus is typically strictly arboreal, and 
TABLE 1 Metrics of capture success for mammalian carnivores at Wildsumaco Wildlife Sanctuary, Ecuador (Fig. 1), with species, mean body mass, percentage of transects occupied, latency to initial detection, number of captures, and trap success.

\begin{tabular}{|c|c|c|c|c|c|}
\hline Species & $\begin{array}{l}\text { Mean body } \\
\text { mass }(\mathrm{kg})\end{array}$ & $\begin{array}{l}\% \text { transects } \\
\text { occupied }^{1}\end{array}$ & $\begin{array}{l}\text { Latency to initial } \\
\text { detection }^{2}\end{array}$ & No. of captures & Trap success ${ }^{3}$ \\
\hline \multicolumn{6}{|l|}{ Felidae } \\
\hline Ocelot Leopardus pardalis & 13.5 & 0.25 & 66 & 4 & 0.0003 \\
\hline Margay Leopardus wiedii & 3.60 & 1.0 & 4 & 103 & 0.0255 \\
\hline Puma Puma concolor & 48.0 & 0.25 & 33 & 9 & 0.0017 \\
\hline Jaguarundi Puma yagouaroundi & 6.75 & 0.25 & 74 & $1^{4}$ & 0.0003 \\
\hline \multicolumn{6}{|l|}{ Mustelidae } \\
\hline Tayra Eira barbara & 4.5 & 0.75 & 40 & $7^{4}$ & 0.0017 \\
\hline Greater grison Galictis vittata & 2.0 & 0.25 & 40 & 1 & 0.0003 \\
\hline Long-tailed weasel Mustela frenata & 0.25 & 0.25 & 16 & 1 & 0.0003 \\
\hline \multicolumn{6}{|l|}{ Procyonidae } \\
\hline South American coati Nasua nasua & 4.75 & 0.25 & 5 & 1 & 0.0003 \\
\hline Kinkajou Potos flavus & 2.75 & 0.25 & 34 & 1 & 0.0003 \\
\hline
\end{tabular}

${ }^{1}$ The proportion of transects on which each species was detected

${ }^{2}$ The number of nights between initiation of sampling and the first record of the species

${ }^{3}$ The number of captures per trap night (number of cameras $x$ the number of nights each camera was operational)

${ }^{4}$ Additional photographic captures of Eira barbara and/or Puma yagouaroundi occurred but because of the nature of the photographs (e.g. partial photographs that only showed a tail) we could not determine species identity unequivocally in some cases. The values reported should therefore be considered the minimum number of independent capture events for each of these species.

M. frenata's low-profile body shape makes it difficult to detect, which is a known problem in surveys of mustelids (O’Connell et al., 2006; Hackett, 2008; Burki et al., 2010).

The Gran Sumaco region encompasses Ecuador's last tracts of undisturbed mid-elevation forest (Neill \& Palacios, 2008), and has been designated a World Biosphere Reserve. This first systematic survey of carnivore species diversity in the region's montane rainforest provides valuable insights into the composition and diversity of eastern Ecuador's mid-elevation carnivore assemblages. Further research on patterns of elevational overlap between species will be important for examining the generality of our findings, for elucidating the environmental conditions and ecological mechanisms that facilitate the existence of diverse carnivore assemblages, and for developing effective conservation and management plans to ensure the long-term viability of carnivores in the Tropical Andes.

\section{Acknowledgements}

This research was supported by the National Science Foundation Graduate Research Fellowship and the Explorer's Club Young Explorer's Grant. We are also grateful to Jim Olson, Bonnie Olson, Jonas Nilsson, the staff at Wildsumaco Wildlife Sanctuary, Santiago Burneo-Nuñez, and other colleagues at the Pontifica Universidad Católica del Ecuador for their generosity in facilitating this fieldwork. Travis Knowles was instrumental as an advisor on the project, and we also thank the many field assistants who contributed to data collection. Finally, we appreciate the anonymous reviewers who provided constructive feedback and valuable advice during the revision process.

\section{References}

Barlow, J., Gardner, T.A., Araujo, I.S., Ávila-Pires, T.C., Bonaldo, A. B., Cost A, J.E. et al. (2007) Quantifying the biodiversity value of tropical primary, secondary, and plantation forests. Proceedings of the National Academy of Sciences, 1054, 18555-18560.

Beisiegel, B.M. \& Zuercher, G.L. (2005) Speothos venaticus. Mammalian Species, 783, 1-6.

Brooks, T.M., Mittermeier, R.A., Mittermeier, C.G., Da Fonseca, G.A.B., Rylands, A.B., Konstant, W.R. et al. (2002) Habitat loss and extinction in the hotspots of biodiversity. Conservation Biology, 16, 909-923.

Burki, S., Roth, T., Robin, K. \& Weber, D. (2010) Lure sticks as a method to detect pine martens Martes martes. Acta Theriologica, 55, 223-230.

Burneo, S.F. (2007) Modelamiento de Distribución Geográfica: Respondiendo a la Pregunta: ¿Dónde? Revista Nuestra Ciencia. Facultad de Ciencias Exactas y Naturales. Pontifica Universidad Católica del Ecuador. Quito.

Cardillo, M., Purvis, A., Sechrest, W., Gittleman, J.L., Bielby, J. \& MACE, G.M. (2004) Human population density and extinction risk in the world's carnivores. PLoS Biology, 2(7), e197.

Colwell, R.K., Rahbek, C. \& Gotelli, N.J. (2004) The mid-domain effect and species richness patterns: what have we learned so far? The American Naturalist, 163, E1-E23.

Di Bitetti, M.S., De Angelo, C.D., Di Blanco, Y.E. \& Paviolo, A. (2010) Niche partitioning and species coexistence in a Neotropical felid assemblage. Acta Oecologica, 36, 403-412.

Elmhagen, B. \& Rushton, S.P. (2007) Trophic control of mesopredators in terrestrial ecosystems: top-down or bottom-up? Ecology Letters, 10, 197-206.

Gerber, B., Karpanty, S.M., Crawford, C., Kotschwar, M. \& RANDRIANANTENAINA, J. (2010) An assessment of carnivore relative abundance and density in the eastern rainforests of Madagascar using remotely-triggered camera traps. Oryx, 44, 219-222.

Gibson, L., Lee, T.M., Koh, L.P., Brook, B.W., Gardner, T.A., BARLOW, J. et al. (2011) Primary forests are irreplaceable for sustaining tropical biodiversity. Nature, 478, 378-381. 
Gompper, M.E., Kays, R.W., Ray, J.C., Lapoint, S.D., Bogan, D.A. \& CRYAN, J.R. (2006) A comparison of noninvasive techniques to survey carnivore communities in northeastern North America. Wildife Society Bulletin, 34, 1142-1151.

Goulart, F.V.B., Cáceres, N.C., Graipel, M.E., Tortato, M.A., Ghizoni, Jr, I.R. \& Oliveira-Santos, L.G.R. (2009) Habitat selection by large mammals in a southern Brazilian Atlantic Forest. Mammalian Biology, 74, 182-190.

Gutiérrez-González, C.E., Gómez-Ramírez, M.Á. \& López-GonzÁlez, C.A. (2012) Estimation of the density of the Near Threatened jaguar Panthera onca in Sonora, Mexico, using camera trapping and an open population model. Oryx, 46, 431-437.

HACKeTt, H.M. (2008) Occupancy modeling of forest carnivores in Missouri. PhD thesis. University of Missouri-Columbia, Columbia, USA.

Hodge, A.M.C. (2012) Methods of niche partitioning between Ecuadorian carnivores and habitat preference of the margay (Leopardus wiedii). Master's thesis. University of North Carolina at Wilmington, Wilmington, USA.

Hodge, A.M.C. (2014) Habitat selection of the margay (Leopardus weidii) in the eastern Andean foothills of Ecuador. Mammalia, 78, 351-358.

Jenkins, C.N., Pimm, S.L. \& Joppa, L.N. (2013) Global patterns of terrestrial vertebrate diversity and conservation. Proceedings of the National Academy of Sciences, 110, E2602-E2610.

Kelly, M.J. (2008) Design, evaluate, refine: camera trap studies for elusive species. Animal Conservation, 11, 182-184.

Kilshaw, K., Johnson, P.J., Kitchener, A.C. \& Macdonald, D.W. (2015) Detecting the elusive Scottish wildcat Felis silvestris silvestris using camera trapping. Oryx, 49, 207-215.

Kluge, J., Kessler, M. \& Dunn, R.R. (2006) What drives elevational patterns of diversity? A test of geometric constraints, climate, and species pool effects for pteridophytes on an elevational gradient in Costa Rica. Global Ecology and Biogeography, 15, 358-371.

LAIDLAW, R.K. (2000) Effects of habitat disturbance and protected areas on mammals of Peninsular Malaysia. Conservation Biology, 14, $1639-1648$.

Lucherini, M., Reppucci, J.I., Walker, R.S., Villalba, M.L., Wurstten, A., Gallardo, G. et al. (2009) Activity pattern segregation of carnivores in the high Andes. Journal of Mammalogy, 90, 1404-1409.

MCCAIn, C.M. (2005) Elevational gradients in diversity of small mammals. Ecology, 86, 366-372.

Michalski, F. \& Peres, C.A. (2005) Anthropogenic determinants of primate and carnivore local extinctions in a fragmented forest landscape of southern Amazonia. Biological Conservation, 124, 383-396.

Neill, D. \& Palacios, W. (2008) Gran Sumaco and Upper Napo River Region, Ecuador. Smithsonian Institution. Http://botany.si. edu/projects/cpd/sa/sa38.htm [accessed 16 November 2012].
O'Connell, JR, A.F., Talancy, N.W., Baily, L.L., SAUER, J.R., Cook, R. \& Gilbert, A.T. (2006) Estimating site occupancy and detection probability parameters for meso- and large mammals in a coastal ecosystem. The Journal of Wildlife Management, 70, 1625-1633.

Poley, L.G., Pond, B.A., Schaefer, J.A., Brown, G.S., Ray, J.C. \& Johnson, D.S. (2014) Occupancy patterns of large mammals in the Far North of Ontario under imperfect detection and spatial autocorrelation. Journal of Biogeography, 41, 122-132.

Quiroga, V.A., Boaglio, G.I., Noss, A.J. \& Di Bitetti, M.A. (2014) Critical population status of the jaguar Panthera onca in the Argentine Chaco: camera-trap surveys suggest recent collapse and imminent regional extinction. Oryx, 48, 141-148.

Ruiz, J.H. (2010) Plan de Manejo Sendero Interpretativo 'Pacto Sumaco -Volcán Sumaco'. Official report. Ministerio de Ambiente Ecuador, Napo, Ecuador.

Shepherd, U.L. \& Kelt, D.A. (1999) Mammalian species richness and morphological complexity along an elevational gradient in the arid south-west. Journal of Biogeography, 26, 843-855.

Silver, S.C., Ostro, L.E.T., Marsh, L.K., Maffei, L., Noss, A.J., KeLly, M.J. et al. (2004) The use of camera traps for estimating jaguar Panthera onca abundance and density using capture/ recapture analysis. Oryx, 38, 148-154.

Tirira, D. (1999) Mamíferos del Ecuador, Volume 2. Museo de Zoología, Centro de Biodiversidad y Ambiente, Pontificia Universidad Católica del Ecuador, Quito, Ecuador.

Tobler, M.W., Carillo-Percastegui, S.E., Leite Pitman, R., Mares, R. \& Powell, G. (2008) An evaluation of camera traps for inventorying large- and medium-sized terrestrial rainforest mammals. Animal Conservation, 11, 169-178.

Vanderhoff, E.N., Hodge, A.M.C., Arbogast, B.S., Nilsson, J. \& Knowles, T.W. (2011) Abundance and activity patterns of the margay (Leopardus wiedii) at a mid-elevation site in the eastern Andes of Ecuador. Mastazoología Neotropical, 18, 271-279.

Woodroffe, R. \& Ginsberg, J.R. (1998) Edge effects and the extinction of populations inside protected areas. Science, 280, 21262128.

\section{Biographical sketches}

Anne-Marie Hodge's research interests lie in biogeography and community ecology, with a focus on the effects of ecological conditions on interspecific interactions between mammalian species. She is currently investigating the ecological dynamics underlying seed dispersal of an invasive cactus by wild mammals and livestock in Kenya. BRIA N ARBOGAST's research combines field studies, population genetics and biogeography to address conservation and evolutionary questions in vertebrates, especially mammals and birds of North America, Australia, and the Tropical Andes of South America. His research group's website is http://people.uncw.edu/arbogastb/lab.html 